\title{
Overexpression of MCPHI inhibits the migration and invasion of lung cancer cells
}

This article was published in the following Dove Press journal: OncoTargets and Therapy

\section{Xiaobin $\mathrm{Wu}^{1-4}$ \\ Wei Liu ${ }^{2-4}$ \\ Xueliang Liu $^{5}$ \\ Qing $\mathrm{Ai}^{1-4}$ \\ Jialin $\mathrm{Yu}^{\mathrm{I}-4}$}

'Department of Neonatology, Children's Hospital of Chongqing Medical University, Chongqing, People's Republic of China; ${ }^{2}$ Children's Hospital of Chongqing Medical University, Ministry of Education Key Laboratory of Child Development and Disorders, Chongqing, People's Republic of China; ${ }^{3}$ Key Laboratory of Pediatrics in Chongqing, Chongqing Medical University, Chongqing, People's Republic of China;

${ }^{4}$ Chongqing International Science and Technology Cooperation Center for Child Development and Disorders, Children's Hospital of Chongqing Medical University, Chongqing, People's Republic of China; ${ }^{5}$ Otolaryngology, The Chongqing Hospital of Traditional Chinese Medicine, Chongqing, People's Republic of China
Correspondence: Jialin Yu Department of Neonatology, Children's Hospital of Chongqing Medical University, I 36 The Second Zhongshan Road, Yuzhong, Chongqing 4000I4, People's Republic of China Email yujialin486@।26.com
Background: The role of dysfunction of $M C P H 1$, a recently identified tumor suppressor gene, has not yet been established in lung cancer. In our previous study, it was reported that $M C P H 1$ expression is downregulated in lung cancer tissues and that $\mathrm{MCPH1}$ overexpression inhibits the proliferation of non-small-cell lung cancer cells. The results can be found in the APJC and Oncology Letters journals.

Methods: Kaplan-Meier survival analysis was conducted to explore the prognostic significance of MCPH1 .Cell experiments were performed to investigate the effects of MCPH1 on the biologic behaviors of lung cancer cells.

Results: In the current study, microarray analysis of MCPH1 revealed that lung cancer patients with high MCPH1 expression had longer relapse-free survival. Overexpression of MCPH1 in A549 lung carcinoma cells successfully inhibited cell migration and invasion. Moreover, overexpression of MCPH1 inhibited migration and invasion by regulating the activities of several proteins that control the epithelial-mesenchymal transition, such as Slug, Snail, E-cadherin, Mdm2, and p53. Conclusion: Our results indicate that downregulation of MCPH1 correlates with tumor progression in lung cancer, and hence MCPH1 may be an important tumor suppressor gene and a novel candidate therapeutic target in lung cancer.

Keywords: MCPH1, migration, invasion, p53, lung cancer, Mdm2

\section{Introduction}

Lung cancer is the leading cause of cancer death worldwide. ${ }^{1,2}$ There are more than 10 million deaths from lung cancer every year, largely because of the lack of effective early diagnosis and treatment. Despite improvements in the availability and sophistication of lung cancer treatment regimens, such as radiotherapy, chemotherapy, and surgery, the 5 -year survival rate remains only $15 \%$ and has not increased significantly over the past 20 years. ${ }^{3}$ Studies of the molecular mechanisms of lung cancer have led investigators and clinicians to focus on gene therapy approaches. Unfortunately, most patients with lung cancer have been diagnosed with distant metastasis, ${ }^{4,5}$ which requires systemic treatment rather than local treatment. It is still difficult to apply gene therapy to systemic disease. ${ }^{6}$

Genetic mutations in $M C P H 1$ result in primary autosomal recessive microcephaly characterized by a significant reduction in brain size, clinical cortical dysplasia, and mental retardation. ${ }^{7,8} \mathrm{MCPH} 1$ encodes a centrosomal protein containing three BRCA1 carboxy-terminal (BRCT) domains. BRCA1 belongs to the BRCT family of proteins that are involved in DNA repair., ${ }^{9,10}$ In addition, MCPH1 is associated with the cell damage response, apoptosis, and cell-cycle regulation.

MCPH1 acts as a tumor suppressor in a variety of cancer cells. ${ }^{11}$ In humans, $M C P H 1$ is located on chromosome $8 \mathrm{p} 23.1$, where loss of chromosomal region is very common in several malignancies such as breast and prostate cancer. In fact, previous BY NG and incorporate the Creative Commons Attribution - Non Commercial (unported, v3.0) License (http://creativecommons.org/licenses/by-nc/3.0/). By accessing the work you
hereby accept the Terms. Non-commercial uses of the work are permitted without any further permission from Dove Medical Press Limited, provided the work is properly attributed. For permission for commercial use of this work, please see paragraphs 4.2 and 5 of our Terms (https://www.dovepress.com/terms.php). 
research demonstrated that $\mathrm{MCPH} 1$ is downregulated in a variety of cancer cells, including cervical cancer, breast cancer, and prostate cancer. ${ }^{8,12}$ Moreover, overexpression of MCPH1 can inhibit the epithelial-mesenchymal transition (EMT) of cervical cancer cells. ${ }^{13}$ In addition, our previous studies revealed that $\mathrm{MCPH} 1$ is downregulated in lung cancer tissues, and it is also involved in the pathogenesis of lung cancer. ${ }^{14,15}$ Therefore, we hypothesized that the absence or low-level expression of MCPH1 may play an important role in the initiation and progression of lung cancer.

In this study, we first evaluated relapse-free survival of patients with lung cancer and found that patients with highlevel MCPH1 expression had significantly longer relapsefree survival than those with low-level MCPH1 expression. Next, we studied the biological effects of MCPH1 in a lung cancer cell line and its possible mechanism. Our findings revealed that MCPH1 overexpression inhibits lung cancer cell migration and invasion by blocking Mdm2-mediated ubiquitination of p53.

\section{Materials and methods}

\section{Survival analysis}

Expression profiling microarray data for human lung cancer clinical specimens were collected from the National Center for Biotechnology Information Gene Expression Omnibus (GEO, http://www.ncbi.nlm.nih.gov/geo/). Relative MCPH1 expression for two microarray datasets, namely, GSE8894 and GSE31210, was assessed with the GEO2R interface (http://www.ncbi.nlm.nih.gov/geo/geo2r/). Survival analysis for non-small-cell lung cancer (NSCLC) patients with different MCPH1 expression levels was performed using the KM plotter database. The prognostic value of MCPH1 was assessed by splitting the patient samples into two groups according to median expression. The survival rate was analyzed with SPSS 17.0 software (IBM Corp., Armonk, NY, USA). Ultimately, 138 patients (in GSE8894) and 204 patients (in GSE31210) were analyzed. This study was approved by the Ethics Committee of Chongqing Medical University. Written informed consent was waived by the Ethics Committee due to data being de-identified and anonymous.

\section{Cell culture and transfection}

The A549 cell lines were purchased from Cell Bank, Shanghai Institutes for Biological Sciences, Chinese Academy of Sciences, Shanghai. A549 human NSCLC cells were cultured in DMEM (Thermo Fisher Scientific, Waltham, MA, USA) supplemented with 10\% heat-inactivated FBS (Thermo Fisher Scientific), penicillin $(50 \mathrm{U} / \mathrm{mL})$, and streptomycin $(50 \mu \mathrm{g} / \mathrm{mL}$; Thermo Fisher Scientific). Cells were maintained at $37^{\circ} \mathrm{C}$ in $5 \% \mathrm{CO}_{2}$ moist air. The constructed pcDNA3.1(-) MCPH1 plasmid was used for cell transfection. ${ }^{15}$ The same number of cells was plated in 24-well and 6-well plates and grown to $80 \%$ confluency. Cells in the 24 -well plates were transfected with $0.5 \mu \mathrm{g}$ pcDNA3.1(-)MCPH1 or empty vector. Cells in the 6-well plates were transfected with $1.0 \mu \mathrm{g}$ pcDNA3.1(-)MCPH1 or empty vector. The specified amounts of vectors were combined in Opti-MEM ${ }^{\mathrm{TM}}$ medium (Thermo Fisher Scientific) with Lipofectamine 2000. The solution was incubated for $30 \mathrm{~min}$ at room temperature and then added to the cultured cells. The medium was changed to DMEM with $10 \%$ FBS after 4 to $6 \mathrm{~h}$.

\section{Wound healing assay}

A horizontal line was drawn on the back of the 6-well plate. The cells $\left(5 \times 10^{5}\right.$ cells/well $)$ were plated overnight in a 6 -well plate. A $200 \mu \mathrm{L}$ pipette tip was used to create a scratch wound across the cells on the plate, and then the plate was washed twice with PBS to remove any floating cells. Serum-free medium was replaced after $24 \mathrm{~h}$, and the closing of each scratch wound was quantified under an inverted microscope.

\section{Analysis of cell migration and invasion}

After $72 \mathrm{~h}$, transfected A549 cells were diluted with serum-free DMEM containing $0.1 \%$ BSA. For the cell migration assay, transfected cells were inoculated into the upper compartment of a transwell chamber and incubated at $37^{\circ} \mathrm{C}$ for $48 \mathrm{~h}$ with the lower chamber, which contained $800 \mu \mathrm{L}$ DMEM with $10 \%$ FBS. The cells were then fixed in methanol and stained with $0.1 \%$ crystal violet. The migrating cells in three randomly selected fields were counted using a light microscope.

For the cell invasion assay, the transfected A549 cells were inoculated into the upper transwell chamber with Matrigel (BD Biosciences, San Jose, CA, USA) and incubated at $37^{\circ} \mathrm{C}$ for $48 \mathrm{~h}$ with the lower chamber, which contained $800 \mu \mathrm{L}$ DMEM with 10\% FBS. The cells were then fixed in methanol and stained with $0.1 \%$ crystal violet. The invading cells in three randomly selected fields were counted using a light microscope.

\section{Western blotting}

Western blotting was performed as previously described. ${ }^{15}$ The proteins were incubated with rabbit monoclonal antihuman IgG to MCPH1 (cat. no ab123361; 1:200 dilution; Abcam, Cambridge, UK), rabbit monoclonal anti- $\beta$-actin IgG (cat. no A0483; 1:100 dilution; Sigma-Aldrich Co., St Louis, MO, USA), rabbit polyclonal anti-Slug IgG (cat. no Ab27568; 1:2,000 dilution; Abcam), rabbit polyclonal anti-Snail IgG (cat. no Ab82846; 1:500 dilution; Abcam), 
rabbit monoclonal anti-E-cadherin IgG (cat. no Ab133597; 1:2,000 dilution; Abcam), rabbit monoclonal anti-p53 (cat. no SAB1306667; 1:500 dilution; Sigma-Aldrich Co.), and mouse monoclonal anti-Mdm2 (cat. no M7815; 1:500 dilution; Sigma-Aldrich Co.).

\section{Statistical analysis}

Data are expressed as the mean \pm SD. Multiple groups of comparative analysis were conducted via one-way analysis of variance and the post hoc Tukey's test, with plasmid treatment as the between-subjects factor. All statistical analyses were performed with the SPSS 17.0 software. $P<0.05$ was considered to reflect a significant difference.

\section{Results}

MCPH1 expression is associated with the survival of lung cancer patients. To study the role of MCPH1 in human lung cancer, microarray datasets with NSCLC or NSCLC specimens were collected from the GEO database. The KM plotter database was used to further investigate the association between MCPH1 expression and clinical outcome. Overall survival of patients with lung cancer was associated with high MCPH1 expression in both datasets (both $P<0.05$; Figure 1). These results suggested that MCPH1 has a protective role in the development of lung cancer.

\section{Overexpression of $\mathrm{MCPHI}$ significantly inhibits A549 cell migration and invasion}

It was recently demonstrated that MCPH1 overexpression inhibits cell proliferation and promotes apoptosis of lung cancer cells. ${ }^{9,10}$ We therefore tested whether MCPH1 could affect lung cancer cell migration and invasion. A549 cells were transfected with pcDNA3.1(-)MCPH1 or empty vector. The wound width of the gap was $100 \mu \mathrm{m}$, and wound healing was observed at 0,24 , and $48 \mathrm{~h}$. The wound healing assay indicated that $\mathrm{MCPH} 1$ overexpression reduced the migration of A549 cells (Figure 2A).

The effect of MCPH1 overexpression on cell migration was then assessed using a transwell assay. The number of A549 cells that migrated through the micropore in the pcDNA3.1(-)MCPH1 group was $25.333 \pm 3.7564$, which was significantly less than that for untreated control cells $(87 \pm 5.0332 ; P=0.0007)$ and for cells transfected with pcDNA3.1 (88.666 $\pm 5.7831 ; P=0.0037$; Figure 2B). This finding also indicated that overexpression of MCPH1 inhibited the migration of A549 cells.

The invasion of A549 cells transfected with pcDNA3.1(-) MCPH1 or empty vector was analyzed with a cell invasion assay. The number of A549 cells that migrated through the micropore in the pcDNA3.1(-)MCPH1 group was $11.666 \pm 1.763$, which was significantly less than for the untreated control cells $(31 \pm 3.055 ; P=0.0027)$ and for cells transfected with pcDNA3.1 $(27 \pm 1.154 ; P=0.0009$; Figure $2 \mathrm{C}$ ). This result indicated that overexpression of MCPH1 inhibited the invasion capacity of A549 cells.

\section{Overexpression of MCPHI inhibits migration and invasion of lung cancer cells through the accumulation of p53}

Our results, to this point, indicated that MCPH1 inhibits the migration and invasion capacities of A549 cells. Cell migration and invasion is associated with certain proteins, such as Slug, Snail, and E-cadherin. ${ }^{16}$ In addition, it has been reported that p53 may suppress the EMT via the p53/Mdm2 pathway, and MCPH1 can regulate $\mathrm{p} 53$ protein. ${ }^{17,18}$ Therefore, we measured the cellular levels of these proteins after MCPH1 overexpression in A549 cells. The results demonstrated that Slug expression in cells transfected with pcDNA3.1(-)MCPH1 was significantly reduced compared with that in untreated
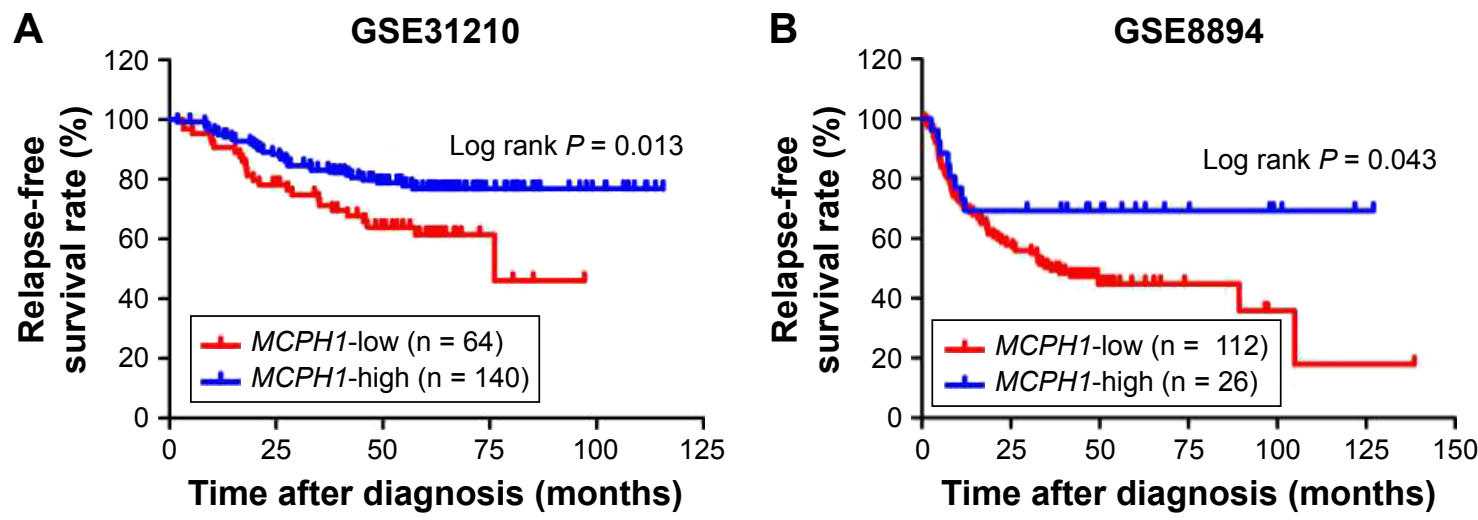

Figure I Kaplan-Meier analysis of $\mathrm{MCPHI}$ expression and the survival rate of patients with non-small-cell lung cancer.

Notes: Overall survival is presented for the low- and high-MCPHI expression groups for two microarray datasets (GSE3।2I0 [A], GSE8894 [B]). The KM plotter database was used for analyses (2015 version). $P<0.05$ was considered as statistically significant. 

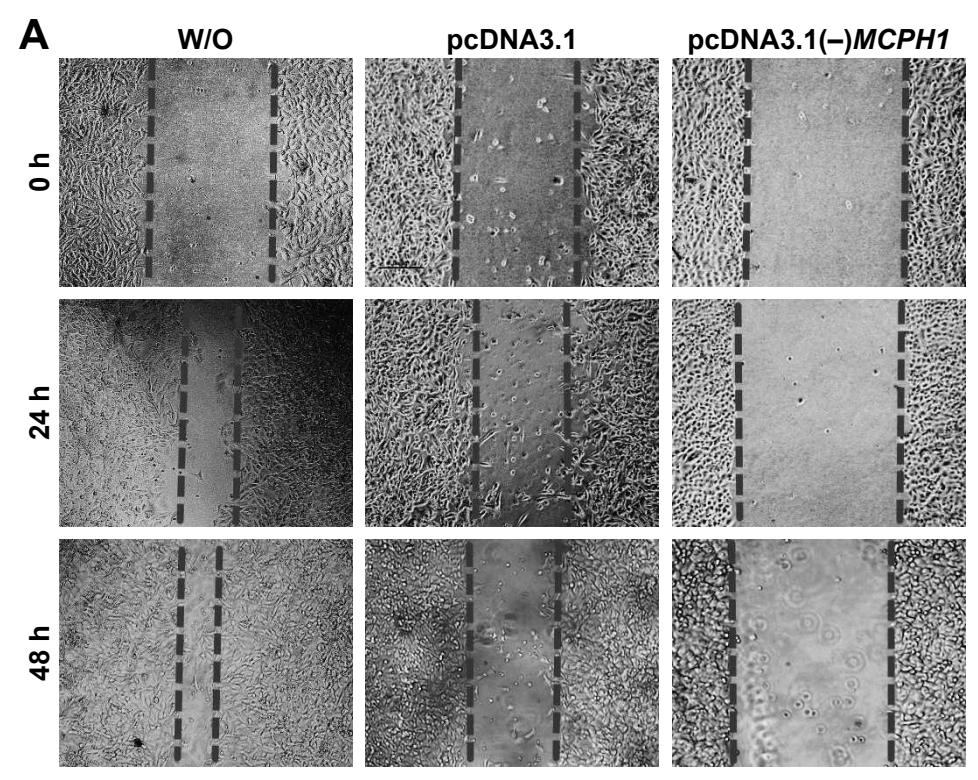

\section{B}
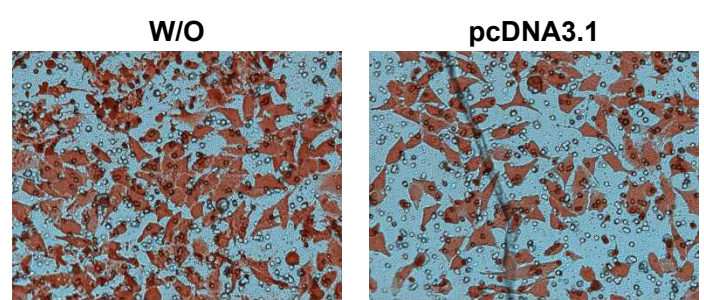

pcDNA3.1(-)MCPH1
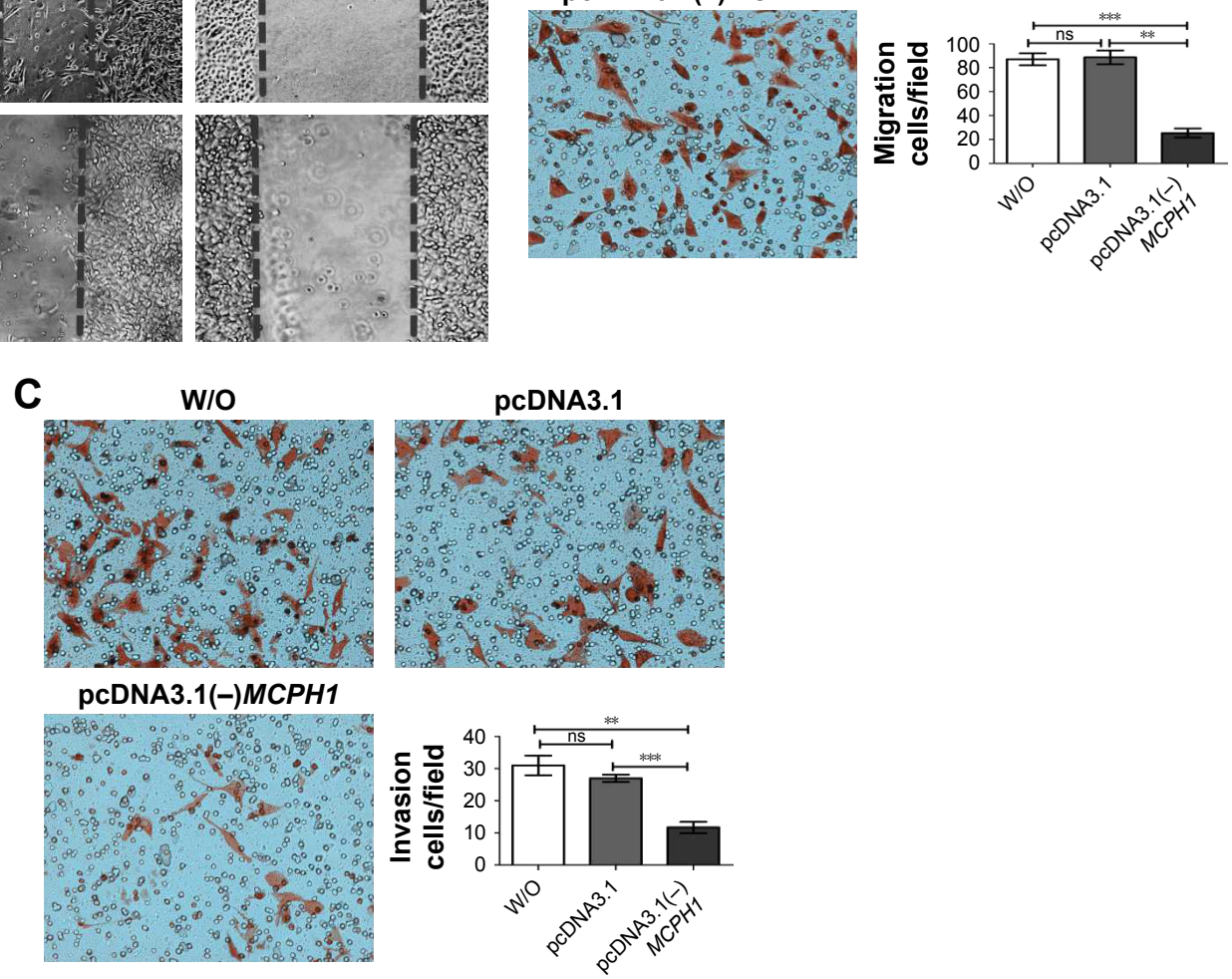

Figure 2 Overexpression of MCPHI inhibits A549 cell migration and invasion.

Notes: $(\mathbf{A})$ The wound healing assay: serial photographs were obtained at the indicated times after wounding in A549 cells. Scale bar=100 $\mu$ m; magnification $\times 100$. (B) Transwell migration assay to assess the effect of $\mathrm{MCPHI}$ overexpression in A549 cells (pcDNA3.I $(-)$ MCPHI) and controls $(\mathrm{W} / \mathrm{O}$ and pcDNA3.I) $(\mathrm{n}=3)$. **P $<0.0 \mathrm{I}$; $* * * P<0.00 I$; ns, no significant difference. (C) Transwell invasion assay to assess the effect of MCPHI overexpression in A549 cells (PCDNA3.I (-)MCPHI) and controls (W/O and pcDNA3.I) $(\mathrm{n}=3)$. Scale bar $=100 \mu \mathrm{m}$; magnification $\times 200$. **P $<0.01$; *** $P<0.00 \mathrm{I}$; ns, no significant difference.

control cells or cells transfected with pcDNA3.1 $(P=0.0049$ and $P=0.0043$, respectively; Figure $3 \mathrm{~A}$ and B). Snail expression in cells transfected with pcDNA3.1(-)MCPH1 was also significantly reduced compared with that in untreated control cells or cells transfected with pcDNA3.1 $(P=0.0152$ and $P=0.0388$, respectively; Figure $3 \mathrm{~A}$ and $\mathrm{B})$. By contrast, the expression of E-cadherin, a factor that antagonizes the EMT, was significantly increased in A549 cells that were transfected with pcDNA3.1(-)MCPH1 as compared with that in untreated control cells or cells transfected with pcDNA3.1 ( $P=0.0042$ and $P=0.0015$, respectively; Figure $3 \mathrm{~A}$ and $\mathrm{B}$ ). These results indicated that MCPH1 overexpression inhibited A549 cell migration and invasion via regulation of the expression of several EMT regulators.
We next explored the pathways by which MCPH1 overexpression inhibits the EMT. Western blotting revealed that $\mathrm{p} 53$ expression in cells transfected with pcDNA3.1(-) MCPH1 was significantly increased compared with that in untreated control cells or cells transfected with pcDNA3.1 ( $P=0.0058$ and $P=0.006$, respectively; Figure $3 \mathrm{~A}$ and B). In addition, Mdm2, which also antagonizes the EMT, was significantly increased in cells transfected with pcDNA3.1(-)MCPH1 compared with that in untreated control cells or cells transfected with pcDNA3.1 $(P=0.0017$ and $P<0.0001$, respectively; Figure $3 \mathrm{~A}$ and $\mathrm{B})$. These results indicated that MCPH1 overexpression may inhibit A549 cell migration and invasion via the upregulation of the cellular level p53. 
A

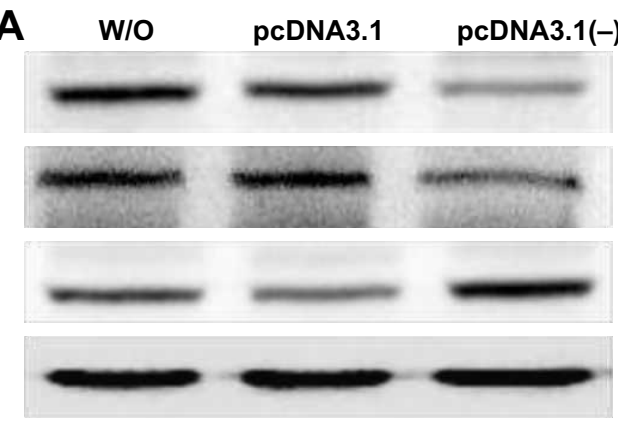

W/O pcDNA3.1

pcDNA3.1(-)MCPH1

Slug

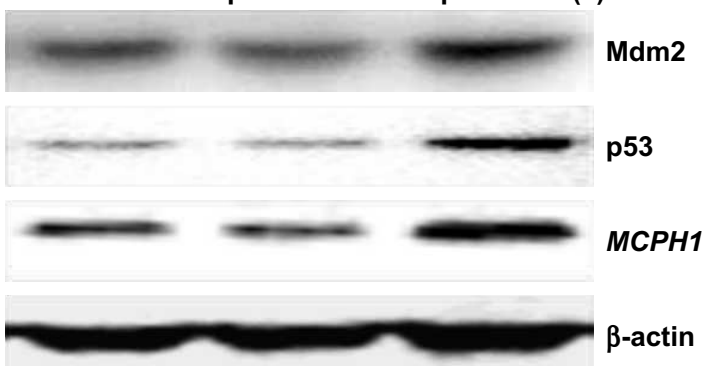

$\beta$-actin
B
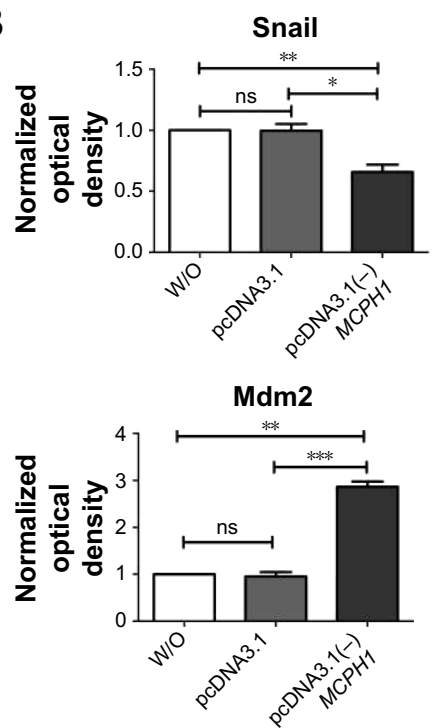
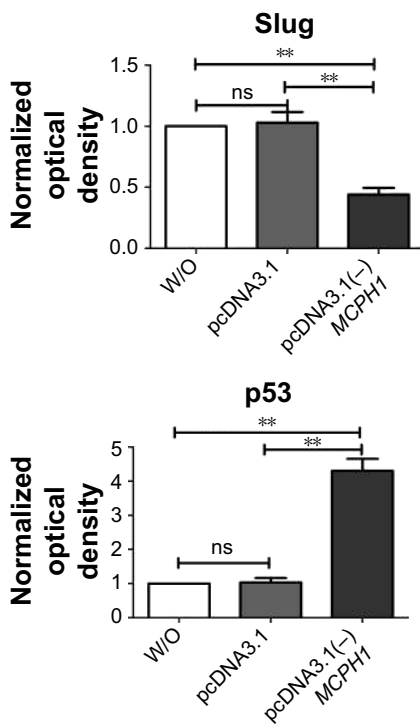
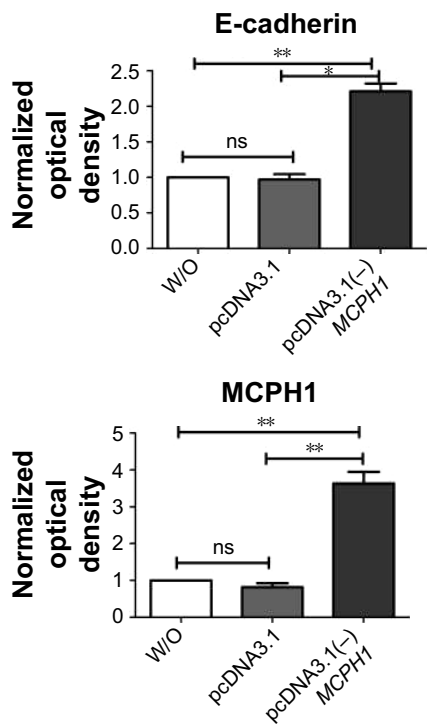

Figure $3 \mathrm{MCPHI}$ inhibits the expression of Snail and Slug by blocking Mdm2-mediated p53 ubiquitination, and thus suppresses invasion and migration of non-small-cell lung cancer cells.

Notes: (A) Western blotting analysis of MCPHI, Slug, Snail, E-cadherin, p53, and Mdm2 in MCPHI-overexpressing A549 cells (pcDNA3.I (-)MCPHI) and control cells (W/O and pcDNA3.I). $\beta$-actin was used as an internal control for equal loading. These data were quantified and graphed in (B). (B) A549 cells transfected with pcDNA3.I (-)MCPHI exhibited significantly increased expression of Mdm2, p53, and E-cadherin and decreased expression of Snail and Slug as compared with the control cells ( $\mathrm{pcDNA3.I}$ and W/O) $(\mathrm{n}=3)$. $* \mathrm{P}<0.05$; $* * P<0.0$ I; $* * * P<0.00$ I; ns, no significant difference.

\section{Discussion}

There are currently many studies of MCPH1 that mainly focused on its role in regulating cell-cycle and pro-apoptotic activities. Multiple studies have demonstrated that MCPH1 has an important role in controlling DNA damage signaling by regulating the ATM/ATR pathway, modifying chromosome structure, and participating in DNA repair. ${ }^{19,20}$ However, it has been demonstrated that, compared with normal tissues, several cancer tissues express much lower concentrations of MCPH1, such as lung cancer, cervical cancer, breast cancer, prostate cancer, and ovarian cancer. Based on these advances, we hypothesized that deletion or low-level expression of MCPH1 may participate in the development of tumors. However, previous studies have not investigated the potential contribution of $\mathrm{MCPH} 1$ mutations to lung cancer. In the present study, our initial results demonstrated that relatively high-level expression of MCPH1 is associated with improved clinicopathological parameters and increased survival of lung cancer patients, and thus, our subsequent studies focused on the role of $\mathrm{MCPHI}$ expression in the migration and invasion potential of lung cancer cells and the underlying mechanism(s).

Previous studies have demonstrated that aberrant underexpression or the expression of MCPH1 is associated with the development of several cancers. ${ }^{21-23}$ In addition, we reported that $\mathrm{MCPH} 1$ is expressed at lower levels in lung tissues and that overexpression of MCPH1 inhibits NSCLC cell proliferation. ${ }^{14,15}$ The present study suggests that MCPH1 plays a role in lung cancer development (Figure 1). Our current results confirm our hypothesis that $\mathrm{MCPH} 1$ deletion or its low-level expression contributes to the development of lung tumors (Figure 1).

Prior to our work, we saw that overexpression of MCPH1 inhibited A549 cell proliferation by increasing apoptosis 
and arresting the cell cycle in S and G2/M phases. ${ }^{15}$ Next, to investigate other potential functions of $\mathrm{MCPH} 1$ in lung cancer cells, the effects of MCPH1 overexpression on migration and invasion were investigated in lung cancer cells. The results revealed that overexpression of MCPH1 inhibited the migration and invasion capacities of A549 cells (Figure 2). These results demonstrate that $\mathrm{MCPH1}$ may function as a suppressor of lung tumorigenesis.

Our present study revealed that MCPH1 overexpression significantly inhibited cancer cell migration and invasion. EMT-associated proteins are key regulators involved in NSCLC migration and invasion. EMT is mainly regulated through the extracellular factor activation of intracellular signal transduction pathways, including those governed by TGF- $\beta /$ Smads, TGF- $\beta$ integrin, Hedgehog, Notch, Wnt/ $\beta$-catenin, MAPK, and PI3K/AKT. ${ }^{24-27}$ The activation of these signaling pathways upregulates genes encoding transcription factors that promote the expression of factors that promote the EMT, such as Snail, Slug, Twist1, Twist2, ZEB1, and ZEB2. ${ }^{28-30}$ In addition, these transcription factors regulate the expression of EMT-associated marker proteins, such as Snail, which can bind directly to the promoter of E-cadherin and inhibit its transcription. ${ }^{31-33}$ Interestingly, we discovered that $\mathrm{MCPHI}$ overexpression inhibited Snail and Slug expression. However, overexpression of MCPH1 upregulated the expression of E-cadherin (Figure 3). These results also indicated that $\mathrm{MCPH} 1$ overexpression inhibited the EMT of lung cancer cells.

A recent study reported that $\mathrm{MCPH} 1$, as a member of the discoidin domain receptor family, is a key regulator of the ATM/ATR pathway ${ }^{10,12,34}$ and also contributes to the modification of chromosome structure REFs and to DNA repair REFs. Interestingly, another study reported that MCPH1 could induce the activation of the ATM/Chk2 and ATR/Chk1 pathways and the phosphorylation of $\mathrm{H} 2 \mathrm{AX}$, as well as delay the progression of cells entering S phase. ${ }^{34}$ Also, MCPH1 regulates $\mathrm{p} 53$ stability by blocking its ubiquitination, which is mediated by Mdm2, and thus, MCPH1 acts as a posttranscriptional regulator of $\mathrm{p} 53 .{ }^{35,36}$ Furthermore, p53 can regulate bcl-2 and bax gene expression as a tumor suppressor, and $\mathrm{Mdm} 2$ can promote the ubiquitination and degradation of Slug and Snail, which are pivotal transcription factors that drive cancer cell invasion. In the present study, overexpression of MCPH1 was shown to increase the expression of $\mathrm{p} 53$ and Mdm2. We postulate that MCPH1 overexpression may inhibit the migration and invasion of lung cancer cells by blocking Mdm2-mediated p53 ubiquitination (Figure 4).

In conclusion, our results strongly suggest that $\mathrm{MCPH1}$ may be a crucial tumor suppressor gene, and thus a candidate

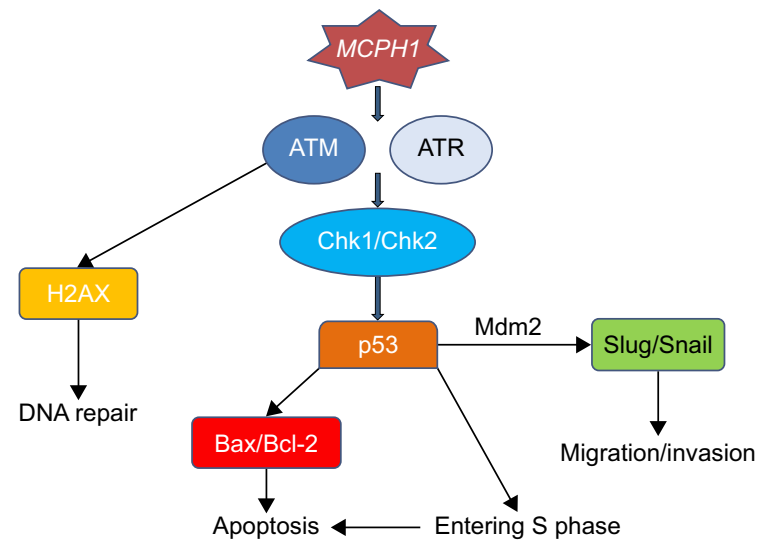

Figure 4 Schematic showing the biological function of $\mathrm{MCPHI}$ in lung cancer cells. Notes: MCPHI has been confirmed as a novel key discoidin domain receptor protein through regulation of the ATM/ATR pathways, modification of the chromosome structure, and DNA repair. It also directly affects cell migration and invasion by blocking the Mdm2-mediated ubiquitination of p53.

therapeutic target for lung cancer. Overexpression of MCPH1 inhibited the migration and invasion of lung cancer cells. MCPH1 inhibited Snail and Slug by blocking Mdm2-mediated p53 ubiquitination, and thus inhibited the invasion and migration capacities of NSCLC cells. These data strongly suggest that $M C P H 1$ may be a crucial tumor suppressor gene and a novel candidate therapeutic target for lung cancer.

\section{Acknowledgment}

This study was supported by Doctoral Degree Funding from Chinese Ministry of Education (no 20135503110009).

\section{Disclosure}

The authors report no conflicts of interest in this work.

\section{References}

1. Pliarchopoulou K, Voutsinas G, Papaxoinis G, et al. Correlation of CYP1A1, GSTP1 and GSTM1 gene polymorphisms and lung cancer risk among smokers. Oncol Lett. 2012;3(6):1301-1306.

2. Torre LA, Siegel RL, Jemal A. Lung Cancer Statistics. Adv Exp Med Biol. 2016;893:1-19.

3. Nanavaty P, Alvarez MS, Alberts WM. Lung cancer screening: advantages, controversies, and applications. Cancer Control. 2014;21(1):9-14.

4. Deng J, Liang H, Sun D, et al. Prognosis of gastric cancer patients with node-negative metastasis following curative resection: outcomes of the survival and recurrence. Can J Gastroenterol. 2008;22(10):835-839.

5. Krüger S, Mottaghy FM, Buck AK, et al. Brain metastasis in lung cancer. Comparison of cerebral MRI and 18F-FDG-PET/CT for diagnosis in the initial staging. Nuklearmedizin. 2011;50(3):101-106.

6. Kadayifci A, Uygun A, Polat Z, et al. Comparison of bismuth-containing quadruple and concomitant therapies as a first-line treatment option for Helicobacter pylori. Turk J Gastroenterol. 2012;23(1):8-13.

7. Trimborn M, Richter R, Sternberg N, et al. The first missense alteration in the MCPH1 gene causes autosomal recessive microcephaly with an extremely mild cellular and clinical phenotype. Hum Mutat. 2005; 26(5):496.

8. Trimborn M, Schindler D, Neitzel H, Hirano T. Misregulated chromosome condensation in MCPH1 primary microcephaly is mediated by condensin II. Cell Cycle. 2006;5(3):322-326. 
9. Ghani-Kakhki M, Robinson PN, Morlot S, et al. Two missense mutations in the primary autosomal recessive microcephaly gene MCPH1 disrupt the function of the highly conserved N-terminal BRCT domain of microcephalin. Mol Syndromol. 2012;3(1):6-13.

10. Jo YH, Kim HO, Lee J, et al. MCPH1 protein expression and polymorphisms are associated with risk of breast cancer. Gene. 2013;517(2): 184-190.

11. Venkatesh T, Nagashri MN, Swamy SS, et al. Primary microcephaly gene MCPH1 shows signatures of tumor suppressors and is regulated by miR-27a in oral squamous cell carcinoma. PLoS One. 2013;8(3): e54643.

12. Arroyo M, Kuriyama R, Trimborn M, et al. MCPH1, mutated in primary microcephaly, is required for efficient chromosome alignment during mitosis. Sci Rep. 2017;7(1):13019.

13. Mai L, Yi F, Gou X, et al. The overexpression of MCPH1 inhibits cell growth through regulating cell cycle-related proteins and activating cytochrome c-caspase 3 signaling in cervical cancer. Mol Cell Biochem. 2014;392(1-2):95-107.

14. Zhang J, Wu XB, Fan JJ, et al. MCPH1 protein expression in normal and neoplastic lung tissues. Asian Pac J Cancer Prev. 2013;14(12): 7295-7300.

15. Zhou L, Bai Y, Li Y, et al. Overexpression of MCPH1 inhibits uncontrolled cell growth by promoting cell apoptosis and arresting the cell cycle in S and G2/M phase in lung cancer cells. Oncol Lett. 2016;11(1) 365-372.

16. Park SH, Cheung LW, Wong AS, Leung PC. Estrogen regulates Snail and Slug in the down-regulation of E-cadherin and induces metastatic potential of ovarian cancer cells through estrogen receptor alpha. Mol Endocrinol. 2008;22(9):2085-2098.

17. Aylon Y, Oren M. New plays in the p53 theater. Curr Opin Genet Dev. 2011;21(1):86-92.

18. Gruber R, Zhou Z, Sukchev M, et al. MCPH1 regulates the neuroprogenitor division mode by coupling the centrosomal cycle with mitotic entry through the Chk1-Cdc25 pathway. Nat Cell Biol. 2011 13(11):1325-1334.

19. Bhattacharya N, Mukherjee N, Singh RK, et al. Frequent alterations of MCPH1 and ATM are associated with primary breast carcinoma: clinical and prognostic implications. Ann Surg Oncol. 2013;20(Suppl 3): S424-S432.

20. Lin SY, Rai R, Li K, Xu ZX, Elledge SJ. BRIT1/MCPH1 is a DNA damage responsive protein that regulates the Brca1-Chk1 pathway, implicating checkpoint dysfunction in microcephaly. Proc Natl Acad Sci US A. 2005;102(42):15105-15109.

21. Liang Y, Gao H, Lin SY, et al. BRIT1/MCPH1 is essential for mitotic and meiotic recombination DNA repair and maintaining genomic stability in mice. PLoS Genet. 2010;6(1):e1000826.

22. Passemard S, El Ghouzzi V, Nasser H, et al. VIP blockade leads to microcephaly in mice via disruption of Mcph1-Chk1 signaling. J Clin Invest. 2011;121(8):3071-3087.
23. Trimborn M, Ghani M, Walther DJ, et al. Establishment of a mouse model with misregulated chromosome condensation due to defective Mcph1 function. PLoS One. 2010;5(2):e9242.

24. Hong F, Wu N, Ge Y, et al. Nanosized titanium dioxide resulted in the activation of TGF-beta/Smads/p38MAPK pathway in renal inflammation and fibration of mice. J Biomed Mater Res A. 2016;104(6): $1452-1461$.

25. Wang W, Olson D, Liang G, et al. Collagen XXIV (Col24alpha1) promotes osteoblastic differentiation and mineralization through TGF-beta/Smads signaling pathway. Int J Biol Sci. 2012;8(10): $1310-1322$.

26. Li J, Zhao Z, Liu J, et al. MEK/ERK and p38 MAPK regulate chondrogenesis of rat bone marrow mesenchymal stem cells through delicate interaction with TGF-beta1/Smads pathway. Cell Prolif. 2010;43(4): 333-343.

27. Yokoyama K, Kimoto K, Itoh Y, et al. The PI3K/Akt pathway mediates the expression of type I collagen induced by TGF-beta2 in human retinal pigment epithelial cells. Graefes Arch Clin Exp Ophthalmol. 2012;250(1):15-23.

28. Gemmill RM, Roche J, Potiron VA, et al. ZEB1-responsive genes in non-small cell lung cancer. Cancer Lett. 2011;300(1):66-78.

29. Pellecchia A, Pescucci C, De Lorenzo E, et al. Overexpression of ETV4 is oncogenic in prostate cells through promotion of both cell proliferation and epithelial to mesenchymal transition. Oncogenesis. 2012;1:e20.

30. Liang X, Zheng M, Jiang J, et al. Hypoxia-inducible factor-1 alpha, in association with TWIST2 and SNIP1, is a critical prognostic factor in patients with tongue squamous cell carcinoma. Oral Oncol. 2011; 47(2):92-97.

31. Rajic J, Inic-Kanada A, Stein E, et al. Chlamydia trachomatis infection is associated with E-cadherin promoter methylation, downregulation of E-cadherin expression, and increased expression of fibronectin and alpha-SMA-implications for epithelial-mesenchymal transition. Front Cell Infect Microbiol. 2017;7:253.

32. Taneyhill LA, Coles EG, Bronner-Fraser M. Snail2 directly represses cadherin6B during epithelial-to-mesenchymal transitions of the neural crest. Development. 2007;134(8):1481-1490.

33. Batlle E, Sancho E, Franci C, et al. The transcription factor snail is a repressor of E-cadherin gene expression in epithelial tumour cells. Nat Cell Biol. 2000;2(2):84-89.

34. Jeffers LJ, Coull BJ, Stack SJ, Morrison CG. Distinct BRCT domains in Mcph1/Brit1 mediate ionizing radiation-induced focus formation and centrosomal localization. Oncogene. 2008;27(1):139-144.

35. Wang SP, Wang WL, Chang YL, et al. p53 controls cancer cell invasion by inducing the MDM2-mediated degradation of Slug. Nat Cell Biol. 2009;11(6):694-704.

36. Lim SO, Kim H, Jung G. p53 inhibits tumor cell invasion via the degradation of snail protein in hepatocellular carcinoma. FEBS Lett. 2010;584(11):2231-2236.
OncoTargets and Therapy

\section{Publish your work in this journal}

OncoTargets and Therapy is an international, peer-reviewed, open access journal focusing on the pathological basis of all cancers, potential targets for therapy and treatment protocols employed to improve the management of cancer patients. The journal also focuses on the impact of management programs and new therapeutic agents and protocols on

\section{Dovepress}

patient perspectives such as quality of life, adherence and satisfaction. The manuscript management system is completely online and includes a very quick and fair peer-review system, which is all easy to use. Visit http://www.dovepress.com/testimonials.php to read real quotes from published authors. 